\title{
Improving patient-reported measures in oncology: a payer call to action
}

\author{
Theresa Schmidt, MA; Tom Valuck, MD, JD; Brittany Perkins, MPH; Jacqlyn Riposo, MBA; Palak Patel, MHA;
} Kimberly Westrich, MA; Ethan Basch, MD, MSc; and Mark McClellan, MD, PhD

\section{SUMMARY}

Despite rising interest in integrating the patient voice in value-based payment (VBP) models for oncology, barriers persist to implementing patient-reported measures (PRMs), including patient-reported performance measures (PR-PMs). This article describes the landscape of oncology PRMs and PR-PMs, identifies implementation barriers, and recommends solutions for public and private payers to accelerate the appropriate use of PRMs in oncology VBP programs.

Our research used a multimethod approach that included a literature review, landscape scan, stakeholder interviews and survey, and a multistakeholder roundtable. The literature review and landscape scan found that limited oncology-specific PR-PMs are available and some are already used in
VBP programs. Diverse stakeholder perspectives provided insight into filling current gaps in measurement and removing implementation barriers, such as limited relevance of existing PRMs and PR-PMs for oncology; methodological challenges; patient burden and survey fatigue; and provider burden from resource constraints, competing priorities, and insufficient incentives. Key recommendations include: (a) identify or develop meaningful measures that fill gaps, engaging patients throughout measure and program development and evaluation; (b) design programs that include scientifically sound measures standardized to reduce patient and provider burden while supporting care; and (c) engage providers using a stepwise approach that offers resources and incentives to support implementation.

\section{Author affiliations}

Theresa Schmidt, MA; Tom Valuck, MD, JD; Brittany Perkins, MPH; Jacqlyn Riposo, MBA; and Palak Patel, MHA, Discern Health, Baltimore, MD. Kimberly Westrich, MA, National Pharmaceutical Council, Washington, DC; Ethan Basch, MD, MSc, UNC Lineberger Comprehensive Cancer Center, Chapel Hill, NC; and Mark McClellan, MD, PhD, Duke-Margolis Center for Health Policy, Durham, NC.

\section{AUTHOR CORRESPONDENCE:}

Theresa Schmidt, 410.542 .4470 x107; tschmidt@discernhealth.com

J Manag Care Spec Pharm 2021;27(1):118-26

Copyright $\odot 2021$, Academy of Managed Care Pharmacy. All rights reserved.
The transition from fee-for-service to value-based payment (VBP) drives quality improvement and cost reduction. ${ }^{1}$ To ensure VBP programs consider how patients and family caregivers define "high-value" care, stakeholders have advanced the use of quality measures that assess and amplify patient perspectives. ${ }^{2}$ Integrating patient voices in VBP is particularly relevant for oncology, where patients are challenged by high symptom burden, psychologic and financial stress, and complicated care pathways. However, incorporating patient perspectives is undermined by barriers, which this paper explores in detail, to implementing meaningful, methodologically sound patient-reported measures (PRMs) and patient-reported performance measures (PR-PMs). PRMs are tools that directly capture patients' perceptions of their experiences and outcomes, whereas PR-PMs are measures built from these tools that capture performance related to these experiences and outcomes over time.

Payers play a substantial role in measuring and incentivizing health care quality. For patient perspectives to be successfully integrated into VBP, payers must drive and support implementation of PRMs and PR-PMs as described below. Payers also benefit from implementation in several ways:

- Patient and physician perceptions of care outcomes and experience often differ, so understanding patient perspectives supports identification of, and payment for, more effective interventions, while promoting patientcentered care. $^{3}$

- PRMs can help payers understand risks and trends at the population level by identifying individuals in need 
of care management and helping providers respond to symptoms earlier. ${ }^{4}$

- Encouraging providers to collect and use PRMs can improve patient outcomes and reduce costs. PRMs have been associated with improved survival, quality of life, and symptom management in oncology. ${ }^{4-6}$ Poorly controlled symptoms and related patient suffering are a common driver of emergency room (ER) visits and hospital admissions. ${ }^{6}$ One study found that $53 \%$ of ER visits by oncology patients could have been prevented with proper symptom management, saving a median $\$ 1,047$ per preventable visit. ${ }^{7}$

Elsewhere, we have described 3 key uses of PRMs and PR-PMs in oncology: enhancing clinical care at the provider level by giving providers information for decisions and facilitating communication; driving and measuring quality improvement at the provider and system levels; and assessing performance for accountability purposes (including VBP) at the provider, system, and population levels. ${ }^{8}$ This paper focuses on the VBP context and describes the landscape of PRM and PR-PM use, barriers to implementation, and actions tailored to payers to advance appropriate use of these measures.

\section{Methods}

Our analysis used a multimethod approach, including a literature review and landscape scan, stakeholder interviews and survey, and a roundtable meeting.

We guided our landscape scan by developing a framework for identifying and describing PRMs and PR-PMs, beginning with selecting these terms. Patient-reported outcome measures (PROMs) are tools that capture direct reports from patients about their care outcomes. ${ }^{9}$ Patientreported outcome performance measures (PRO-PMs) are measures constructed from PROMs that assess performance on outcomes over time. ${ }^{10}$ We expanded on these concepts by using the terms "PRM" and "PR-PM" to emphasize the need to assess patient-reported facets of care and experience beyond clinical outcomes. These include access to care, shared decision making, and patient engagement or education. "PRM" is a commonly used term, although not as common as "PROM", but a search of PubMed revealed no results for the terms "patient-reported performance measure" or "PR-PM."

Our framework includes 3 care phase domains that build on the National Quality Forum (NQF)'s Patient-Focused Episode of Care Model for Cancer and were validated using the National Voluntary Consensus Standards for Quality of Cancer Care. ${ }^{11,12}$ It also includes 14 content domains related to quality of life and experience of care that were derived from comparing and contrasting several other measurement frameworks and modified to better describe the measures identified in the landscape scan. ${ }^{13-16}$

We used the NQF Quality Positioning System (QPS), Agency for Healthcare Research and Quality (AHRQ) National Quality Measures Clearinghouse (NQMC), Centers for Medicare \& Medicaid Services (CMS) Quality Measures Inventory, and gray literature to identify the availability of PRMs and PR-PMs. To ensure we included the most recent information, we also visited the websites of public-facing oncology-related accountability programs known to the industry and identified in previous work, including VBP programs, to identify PRMs and PR-PMs included in those measure sets. The initial scan captured PR-PMs available as of April 2018; we updated the oncology VBP program measure scan in May 2020. (The NQMC was removed from the AHRQ website in July 2018. Measures included in the landscape scan were collected and assessed before that.)

The landscape scan informed 17 interviews with 18 stakeholders (1 interview had 2 people) in oncology, quality measurement, and VBP to gain perspectives about development and use of PRMs and PR-PMs in oncology VBP. These semistructured interviews were conducted on the telephone with one primary interviewer and a secondary notetaker. Ahead of the interview, each interviewee was given a discussion guide, which served as the backbone of the conversation while allowing flexibility. Additionally, we administered a brief survey via Survey Monkey to interviewees and roundtable convening invitees. The survey had 15 questions, including a mix of multiple choice and open-ended response options. We received 18 responses, which informed the roundtable discussion.

Twenty-four experts participated in the September 2018 roundtable. We selected participants with previous experience working with PRMs, performance measures, oncology research, and/or oncology patients. These experts offered insight from oncology care, regulatory/policy, quality measurement, employer purchasing, academic research, health insurance, and patient experience. In addition to patient advocacy organizations, the roundtable also included an oncology patient receiving active treatment and a cancer survivor. The highly interactive 1-day roundtable began with a patient panel and included a review of the landscape and survey findings, guided group discussions, round-robin sharing, and dot voting. The roundtable dialogue informed our recommendations for filling gaps in oncology PRMs and PR-PMs and removing barriers to implementation that impact patients, providers, and payers in oncology VBP programs.

Two patients participated in this project as subject matter experts. The research was not covered by the U.S. 


\section{FIGURE 1 Oncology PR-PMs per Domain ${ }^{\mathrm{a}}$}

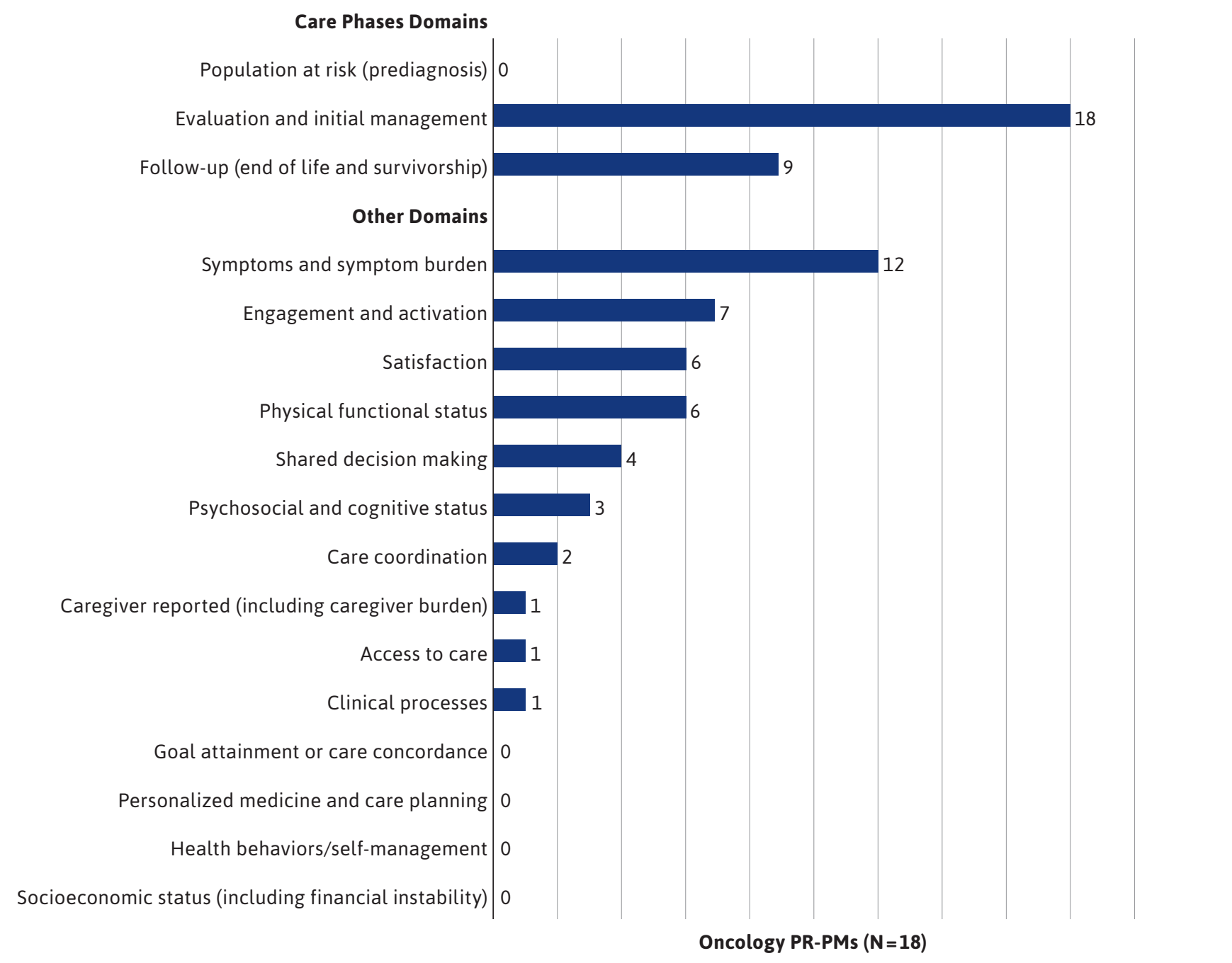

aSome PR-PMs capture multiple domains.

$P R-P M=$ patient-reported performance measure.

Department of Health and Human Services regulations for Activity Human Subjects Research and did not require institutional review board approval.

\section{Results}

\section{AVAILABILITY OF PRMS AND PR-PMS}

The landscape scan identified a universe of more than 800 PR-PMs, including 515 crosscutting measures applicable to oncology and 18 oncology-specific PR-PMs. These findings illustrate that, although a large pool of PR-PMs is available, very few are specific to oncology. However, some of the many crosscutting PR-PMs might be considered for inclusion in an oncology VBP program if they capture concepts that are meaningful to patients, are relevant to the program, and can be tested in the program population. We also identified 106 oncology-specific PRMs and 155 crosscutting PRMs. Not all PRMs were associated with PR-PMs, and some of the oncology-specific PR-PMs are based on crosscutting PRMs.

Figure 1 shows the distribution of PR-PMs across measure domains, with some falling into multiple domains. 


\section{TABLE 1}

PRMs and PR-PMs in CMS Oncology VBP Programs (Updated May 2020)

\begin{tabular}{|c|c|c|}
\hline Program & PR-PM & Note \\
\hline \multirow[t]{2}{*}{$\mathrm{PCHQR}^{45}$} & $\begin{array}{l}\text { PCH-16 (NQF 0384): Oncology: } \\
\text { medical and radiation-pain } \\
\text { intensity quantified }\end{array}$ & $\begin{array}{l}\text { Process measure: Not a PR-PM, } \\
\text { but component "pain intensity } \\
\text { quantified" indicates the presence } \\
\text { of pain through use of a PRM }\end{array}$ \\
\hline & $\begin{array}{l}\text { PCH-29 (NQF 0166): HCAHPS } \\
\text { Survey } \\
\text { - Communication with doctors } \\
\text { - Communication with nurses } \\
\text { - Responsiveness of hospital staff } \\
\text { - Communication about medicines } \\
\text { - Discharge information } \\
\text { - How well patients understood } \\
\text { the care they would need after } \\
\text { leaving the hospital } \\
\text { - Cleanliness of the hospital } \\
\text { environment } \\
\text { - Quietness of the hospital } \\
\text { environment } \\
\text { - Overall rating of the hospital } \\
\text { - Recommendation of the hospital }\end{array}$ & $\begin{array}{l}\text { An 11th measure related to pain } \\
\text { control was removed per the } 2020 \\
\text { Hospital Inpatient Prospective } \\
\text { Payment Systems Final Rule to } \\
\text { address concerns related to opioid } \\
\text { prescribing }\end{array}$ \\
\hline \multirow[t]{3}{*}{$\mathrm{OCM}^{46,47}$} & $\begin{array}{l}\text { OCM-4a (NQF 0384): Oncology: } \\
\text { medical and radiation-pain } \\
\text { intensity quantified }\end{array}$ & $\begin{array}{l}\text { Process measure: Not a PR-PM, } \\
\text { but component "pain intensity } \\
\text { quantified" indicates the presence } \\
\text { of pain through use of a PRM }\end{array}$ \\
\hline & $\begin{array}{l}\text { OCM-5 (NQF 0418): Preventive } \\
\text { care and screening for depression } \\
\text { and follow-up }\end{array}$ & $\begin{array}{l}\text { Process measure: Not a PR-PM, } \\
\text { but provider screening of patients } \\
\text { uses a PRM and subsequent care } \\
\text { planning if screened positive }{ }^{48}\end{array}$ \\
\hline & $\begin{array}{l}\text { OCM-6: Patient-reported } \\
\text { experience of care }\end{array}$ & $\begin{array}{l}\text { Patient-reported experience } \\
\text { measure }\end{array}$ \\
\hline $\begin{array}{l}\text { MIPS General } \\
\text { Oncology Measure } \\
\text { Set }^{49}\end{array}$ & $\begin{array}{l}\text { MIPS 0384e (NQF 0384): } \\
\text { Oncology: medical and } \\
\text { radiation-pain intensity } \\
\text { quantified }\end{array}$ & $\begin{array}{l}\text { Process measure: Not a PR-PM, } \\
\text { but component "pain intensity } \\
\text { quantified" indicates the presence } \\
\text { of pain through use of a PRM }\end{array}$ \\
\hline $\begin{array}{l}\text { MIPS Radiation } \\
\text { Oncology Measure } \\
\text { Set }^{50}\end{array}$ & $\begin{array}{l}\text { MIPS 0384e (NQF 0384): } \\
\text { Oncology: medical and } \\
\text { radiation-pain intensity } \\
\text { quantified }\end{array}$ & $\begin{array}{l}\text { Process measure: Not a PR-PM, } \\
\text { but component "pain intensity } \\
\text { quantified" indicates the presence } \\
\text { of pain through use of a PRM }\end{array}$ \\
\hline \multirow[t]{2}{*}{$\begin{array}{l}\text { Oncology-specific } \\
\text { MIPS QCDRs }\end{array}$} & $\begin{array}{l}\text { ONSQIR21: Patient-reported } \\
\text { HRQOL during treatment for } \\
\text { advanced cancer }\end{array}$ & PRO-PM \\
\hline & $\begin{array}{l}\text { PIMSH4: Oncology: patient- } \\
\text { reported pain improvement }\end{array}$ & PRO-PM \\
\hline
\end{tabular}

${ }^{a}$ Four oncology-specific PR-PMs were removed from MIPS QCDRs in 2020.

HCAHPS = Hospital Consumer Assessment of Healthcare Providers and Systems; HRQOL=health related quality of life; MIPS = Merit-Based Incentive Payment System; NQF = National Quality Forum; $O C M=$ Oncology Care Model; $P C H Q R=$ Prospective Payment System-Exempt Cancer Hospital Quality Reporting; $P R M=$ patient-reported measure; $P R O-P M=$ patient-reported outcome performance measure; $P R-P M=$ patient-reported performance measure; $Q C D R=$ Qualified Clinical Data Registry; $\mathrm{VBP}=$ value-based payment.
Our analysis revealed large gaps in the availability of oncology-specific PRMs and PR-PMs related to goal attainment or care concordance, personalized medicine and care planning, socioeconomic status and financial instability, and the population-at-risk phase of cancer care (prediagnosis). Additionally, we identified only 1 caregiver-reported PR-PM, and it did not capture caregiver burden. Likewise, PR-PMs and PRMs that address the follow-up phase of cancer care (posttreatment) generally focused on end of life and did not capture survivorship. Although we found no oncologyspecific PR-PMs that assess health behaviors and self-management, this area was better represented with crosscutting PR-PMs.

Landscape findings correspond to the observations of survey participants who identified care coordination (60\%) as a high-priority domain of PR-PMs for inclusion in VBP followed by access to care (56\%) and symptoms/symptom burden (56\%). Supplementary Figure 1 (available in online article) displays the percentage of survey respondents that selected "high priority" for each domain.

\section{PRM AND PR-PM USE IN VBP}

CMS has implemented VBP programs that use PRMs to determine provider payment and improve care delivery. ${ }^{17}$ Several CMS programs include PRPMs for an oncology population or clinical process measures that capture PRM use. For example, the Center for Medicare and Medicaid Innovation (CMMI) Oncology Care Model (OCM) includes a patient experience PR-PM and 2 process measures that capture whether providers assessed patientreported pain or depression using a standard instrument (i.e., a PRM) and completed care planning if the patient screened positive. ${ }^{18-20}$

The oncology-related CMS VBP programs that include PR-PMs or 
PRM-related measures are the OCM, the Prospective Payment System-Exempt Cancer Hospital Quality Reporting program (PCHQR), and oncology-specific Qualified Clinical Data Registries for the Merit-Based Incentive Payment System (MIPS; Table 1).

CMMI is testing additional models featuring PRMs or PR-PMs, such as the proposed Radiation Oncology Model and proposed Oncology Care First Model (OCF). ${ }^{21-23}$ Other stakeholders have submitted oncology payment models that include PRMs to the Physician-Focused Payment Model Technical Advisory Committee (PTAC), such as the PTACrecommended Making Accountable Sustainable Oncology Networks alternative payment model. ${ }^{24,25}$

VBP arrangements are also prevalent among private payers, who have begun to implement PRMs and PR-PMs. For example, the Community Health Plan of Washington became 1 of the first private payers to implement PROMs as clinical quality measures in 2018. ${ }^{26}$ The interviews and roundtable also discussed how private payers use PR-PMs or PRMs. A health plan representative for 1 organization explained that its contracts require providers to collect and report PRMs but have not yet tied PR-PM performance to payment. Another stakeholder noted that some private payers have included National Committee for Quality Assurance (NCQA) Oncology Medical Home Recognition, which includes several PR-PMs and PRM-related measures, in provider VBP programs. ${ }^{27}$ Although NCQA retired this recognition program in October 2019, it encourages practices to instead pursue the Patient-Centered Specialty Practice Recognition program, which requires that practices conduct a patient experience survey (i.e., a PRM) that covers at least 3 of the following concepts: access, communication, care coordination, and person-centered care/ self-management support. ${ }^{28,29}$

Collaborations between the public and private sectors have further increased use of PR-PMs in payment and other accountability programs. America's Health Insurance Plans, CMS, and NQF have partnered through the Core Quality Measure Collaborative (CQMC) to promote public and private payer alignment in measures used for quality improvement, transparency, and payment purposes. ${ }^{30}$ The CQMC prioritized inclusion of "innovative measures," such as PR-PMs, in its core measure sets. ${ }^{31}$

\section{BARRIERS TO IMPLEMENTING PRMS IN VBP}

Though payers have begun to incorporate PRMs and PRPMs in VBP, the interviews, survey, and roundtable discussion identified several key barriers, discussed in the following sections.

Meaningfulness of Measures. The promise of VBP is that payment will be tied to value. However, the way VBP programs define value, and the PRMs and PR-PMs used to assess it, may not always be meaningful to patients and caregivers. Defining value may be especially complicated for the heterogeneous population of oncology patients challenged with navigating a complex health care system while shouldering physical, social, psychological, and financial burdens. Different patients may have different goals, preferences, and values. For 1 cancer patient, managing pain may be the most important priority, whereas another might value remaining alert. For the latter patient, a PR-PM that assesses level or frequency of pain may be less meaningful than one that captures symptom burden, such as days of work missed. Even when measures address meaningful concepts, they may be specified in a way that is less meaningful. For example, many PRMs capture symptoms, like pain, at a given point in time and miss overall symptom burden.

Methodological Challenges. Roundtable stakeholders agreed that PR-PMs should be held to a higher technical standard when used in accountability programs to ensure that regulatory or financial consequences are tied to accurate assessment of provider performance. Underlying PRMs must fit the purposes they serve, which should drive payer selection of relevant PRMs and PR-PMs. PR-PMs must be valid, reliable, and consider potential sources of bias such as small denominators for some cancer types, sociodemographic or clinical characteristics, and patient desire to "protect" providers.

Patient Burden and Survey Fatigue. Cancer patients interact with the health care system frequently and receive many surveys from various providers. Resulting survey fatigue could be exacerbated by irrelevant and/or complex questions. Additionally, lack of coordination between providers and programs may result in requests for duplicative information. Absence of integrated electronic health record (EHR) systems and flow of information between providers and payers may also contribute to survey duplication.

Provider Burden. Providers may not have resources to implement PRMs in their clinical workflows. Additionally, providers must meet requirements of multiple accountability programs, many of which do not provide sufficient incentives to offset investment needed to implement PRMs and report PR-PMs.

\section{Recommendations for Accelerating Progress}

Our multimethod analysis yielded actionable recommendations for public and private payers to increase appropriate use of PRMs and PR-PMs in oncology VBP programs. Because much activity is underway, these recommendations 
focus on accelerating progress through measure development, program design, and implementation.

\section{SUPPORT DEVELOPMENT OF MEANINGFUL MEASURES}

Some public and private payers develop measures or fund measure development. To capture elements of care process and experience that are most meaningful to cancer patients, payers should engage patients and caregivers in development and ongoing evaluation of PRMs and PR-PMs.

Development work should aim to fill current gaps in availability of oncology PRMs and PR-PMs: goal attainment or care concordance, personalized medicine and care planning, socioeconomic status and financial instability, population at risk, caregiver burden, and survivorship. Payers could leverage existing crosscutting PRMs to develop oncology-specific PR-PMs to fill some of these gaps. Public payers can also fill current gaps by offering measure development grants and continuing to fund relevant initiatives. For example, the CMS Meaningful Measures initiative and the Department of Health and Human Services Quality Summit demonstrate a move toward outcome measures that are meaningful to patients..$^{32,33}$

Payers developing or modifying PRMs should eliminate questions that are less useful or meaningful to increase patient response rate and generate more accurate data. If PRMs are available in a platform that allows patients to skip irrelevant questions, while maintaining validity and reliability, overwhelmed cancer patients will have less burden from completing extensive surveys.

Private payers can collaborate with measure developers and professional societies to generate new measures and may have capacity to create and implement custom measures to apply to their networks. For example:

- Optum, a part of UnitedHealth Group, is listed as steward for 10 quality measures in the NQF QPS (identified using the "measure steward" filter). ${ }^{34}$

- ActiveHealth Management, a population health management company and subsidiary of Aetna, stewards 28 measures in the QPS. ${ }^{34,35}$

- HealthPartners, an integrated health care organization with a health plan, has developed measures for over a decade. ${ }^{36,37}$

Private payers should also participate in national efforts to create appropriate PRMs and PR-PMs. For example, the CQMC has identified "patient experience/PRO for level of pain experienced by patient" as a future development opportunity in its Medical Oncology Consensus Core Set to be implemented across commercial and government payers. ${ }^{38,39}$ Payers could also explore opportunities to participate in collaborative projects related to patient-centered measurement funded by organizations like the PatientCentered Outcomes Research Institute. ${ }^{40}$

\section{SELECT MEANINGFUL, SCIENTIFICALLY SOUND, AND STANDARDIZED MEASURES FOR PROGRAMS}

Public and private payers should involve patients and caregivers in the design of VBP programs and include patient involvement in development as 1 criterion for selecting PRPMs for program use. Payers can also promote use of meaningful measures by selecting PR-PMs that address areas identified as priorities on the survey and in the roundtable, such as care coordination, access to care, and symptoms/ symptom burden, for new programs or future versions of programs such as OCM/OCF. Measures of symptom management, specifically, can help payers identify at-risk patients, improve population health management, and decrease utilization of health care services.

Payers should select valid, reliable, and fit-for-purpose PRMs and PR-PMs for value-based programs to ensure that providers are fairly assessed on measures that affect their payment. Using PR-PMs that have been endorsed by NQF is one way to ensure validity and reliability. ${ }^{41}$ Additionally, many published PRMs include measure testing results, describe the population on which the PRM was tested, and discuss the psychometric properties. This may help a payer determine if the measure is valid, reliable, and has been used in a similar setting.

To address bias related to small denominators in rarer cancer types, program designers should include crosscutting PR-PMs, address measures at the group or system level, and consider combining multiple years of data. Crosscutting measures may also better encompass diverse cancer types and treatments in broader VBP programs.

Payers should work to align PRMs and PR-PMs across programs and select standard PR-PMs and/or PR-PMs built from standard PRMs to reduce provider and patient burden. Selecting crosscutting PR-PMs derived from PRMs that also have condition-specific questions may decrease burden and improve care by enabling providers to use the same instrument for clinical care, quality improvement, and accountability purposes.

\section{INCENTIVIZE IMPLEMENTATION}

Payers and program administrators should use a stepwise approach to engage providers in implementation:

1. Offer incentives and provide resources, like technology, to assist providers in initial implementation of new programs.

2. Set realistic expectations for implementation and performance, establishing thresholds for providers to use as benchmarks. 
3. Allocate implementation time for providers and programs to gather and analyze data.

4. Use a learning feedback loop to calibrate approaches to improve program structure, PRMs, and PR-PMs.

5. Give providers time and information to improve both PRM administration and PR-PM performance.

6. Institute VBP and begin evaluating additional PR-PMs.

The first of these steps is critical. Implementing PRMs can require substantial resources, and without strong incentives, providers may not be willing to undergo the effort. Public and private payers can drive change by offering training, grants, resources, and additional incentives to fund implementation and administration of PRMs and PR-PMs in VBP programs. For example, payers could offer a per member per month (PMPM) payment for providers to implement PRMs as a component of oncology infrastructure improvements. PMPM payments would incentivize implementation and enable providers to use PRMs to better manage oncology patients and populations. This could reduce public and private payer costs via patient-centered efforts to better control symptoms, reduce unplanned utilization, and improve patient experience of care.

Payers should offer technology, or funding for technology, to capture symptoms and symptom burden, beginning with initiation of cancer treatment. For example, CMS could offer subsidies for EHR vendors to incorporate standardized PRMs into their systems. Private payers might supply PRM software to network providers at no charge. Technology can help providers assess and respond to symptoms throughout treatment, allowing payers to avoid downstream costs, such as unnecessary ER visits. The National Health Service of the
United Kingdom has advanced PRM technology by publishing a CancerRelated Fatigue application that helps patients manage symptoms, reducing fatigue and increasing happiness. ${ }^{42}$ In France, a randomized trial found an association between monitoring lung cancer symptoms via web-based PROs and increased survival. ${ }^{43}$ Web-based surveillance is also cost-effective compared to conventional surveillance. ${ }^{44}$

\section{Conclusions}

Cancer patients face many challenges, including navigating a complex health care system while experiencing high symptom, psychological, and financial burdens. Their perspectives are paramount to understanding quality and value of care they receive. Using PRMs and PR-PMs not only captures the value of cancer care from patients' perspectives but can also hold providers accountable for patient needs, improve patient experience and outcomes, and reduce costs for payers.

Payers play a critical role in defining value, shaping provider behavior, and influencing patient outcomes in oncology. By supporting meaningful PRM and PR-PM development, designing programs with appropriate PRMs and PR-PMs, and incentivizing implementation, payers can help ensure that VBP programs promote delivery of patient-centered, high-value care for cancer patients and their families. Payers should commit to continuously improving oncology-related PRMs, PR-PMs, and value-based programs that use them.

\section{DISCLOSURES}

Funding for this project was provided by the National Pharmaceutical Council. Schmidt, Perkins, Riposo, and Patel are employees of Discern Health, a consulting firm with many clients, including government, life sciences, nonprofit, and provider organizations. Valuck is a partner at Discern Health. Westrich is an employee of the National Pharmaceutical Council, an industry-funded health policy research group that is not involved in lobbying or advocacy. Basch reports grants from National Cancer Institute and Patient-Centered Outcomes Research Institute; fees from serving as a consultant on research projects at Memorial Sloan Kettering Cancer Center, Dana-Farber Cancer Institute, and Research Triangle Institute/CMS; and fees from serving as a scientific advisor to CareVive Systems, Sivan Healthcare, Navigating Cancer, and AstraZeneca, outside the submitted work. McClellan reports fees from serving on the boards of Johnson \& Johnson and Seer Bio and as an advisor to Cota outside the submitted work; and McClellan is an independent board member on the boards of Cigna and Alignment Healthcare, co-chair of the Guiding Committee for the Health Care Payment Learning and Action Network, and receives fees for serving as an advisor for MITRE, outside the submitted work.

\section{ACKNOWLEDGMENTS}

The authors thank the following individuals for their contributions to the project (affiliations current as of the September 2018 roundtable): Joseph Alvarnas (City of Hope), Andrew Baskin (Aetna), John Bernot (National Quality Forum), Rachel Brodie (Pacific Business Group on Health), W. Garth Callaghan (Napkin Notes Dad), Andrea Ferris (LUNGevity), Karen Fields (Moffit Cancer Center), C. Lyn Fitzgerald (National Comprehensive Cancer Network), Jennifer Griggs (representative for the American Society of Clinical Oncology), Cynthia Grossman (FasterCures, a center of the Milken Institute), Linda House (Cancer Support Community), Roxanne Jensen (National Cancer Institute), Jeremy Nobel (Harvard Medical School, formerly of the Northeast Business Group on Health), Stacey Moser (patient representative; The Leukemia and Lymphoma Society), Sally Okun (PatientsLikeMe), Collette Pitzen (MN Community Measurement), Kristen Santiago (Cancer Support Community), Ann Steagall (Biologics, Inc.), Katherine Szarama (Center for Clinical Standards and Quality, CMS), Manasi Tirodkar (National Committee for Quality Assurance), Andrew York (Center for Medicare and Medicaid Innovation, CMS), Emily Wilson (American Society for Radiation Oncology), and Yousuf Zafar (Duke Cancer Institute). 


\section{REFERENCES}

1. RevCycleIntelligence. What is valuebased care, what it means for providers? June 7, 2016. Accessed September 17, 2020. https://revcycleintelligence.com/features/what-is-value-based-care-what-itmeans-for-providers

2. National Quality Forum. Patient-reported outcomes. 2020. Accessed September 17, 2020. https://www.qualityforum.org/ Patient-Reported Outcomes.aspx

3. Millenson ML; Health Quality Advisors and the National Partnership for Women and Family. Building patient-centeredness in the real world: the engaged patient and Accountable Care Organization. Accessed September 17, 2020. http://www.nationalpartnership.org/our-work/resources/ health-care/building-patient-centeredness-in-the-real-world.pdf

4. Basch E, Deal AM, Dueck AC, et al. Overall survival results of a trial assessing patient-reported outcomes for symptom monitoring during routine cancer treatment. JAMA. 2017;318(2):197-98.

5. Zhang B, Lloyd W, Jahanzeb M, Hassett MJ. Use of patient-reported outcome measures in Quality Oncology Practice Initiative-registered practices: results of a national survey. J Oncol Pract. 2018;14(10): e602-11.

6. Basch E, Deal AM, Kris MG, et al. Symptom monitoring with patient-reported outcomes during routine cancer treatment: a randomized controlled trial. J Clin Oncol. 2016;34(6):557-65.

7. American Society of Clinical Oncology. ASCO 2017: many emergency department visits among patients with cancer appear preventable. June 7, 2017. Accessed September 17, 2020. https://www.ascopost.com/News/55724

8. National Pharmaceutical Council. Improving patient-reported measures in oncology. 2019. Accessed September 17, 2020. https://www.npcnow.org/system/ files/research/download/2019-improving-patient-reported-measures-in-onco$\underline{\text { logy-final-accessible.pdf }}$
9. Weldring T, Smith SM. Patient-reported outcomes (PROs) and patient-reported outcome measures (PROMs). Health Serv Insights. 2013;6:61-68.

10. Katzan IL, Fan Y, Griffith SD, Crane PK, Thompson NR, Cella D. Scale linking to enable patient-reported outcome performance measures assessed with different patient-reported outcome measures. Value Health. 2017;20(8):1143-1149.

11. National Quality Forum. Cancer 20152017 draft report. July 8, 2016. Accessed September 17, 2020. http://www. qualityforum.org/Projects/c-d/Cancer Project_2015-2017/Draft_Report_for_ Comment.aspx

12. National Quality Forum. National voluntary consensus standards for quality of cancer care. May 2009. Accessed September 17, 2020. https://www.qualityforum.org/Publications/2009/05/National_ Voluntary_Consensus_Standards_for_ Quality_of_Cancer_Care.aspx

13. Basch E, Snyder C, McNiff K, et al. Patient-reported outcome performance measures in oncology. J Oncol Pract. 2014;10(3):209-11.

14. Valuck T, Blaisdell D, Dugan DP, et al. Improving oncology quality measurement in accountable care: filling gaps with cross-cutting measures. J Manag Care Spec Pharm. 2017;23(2):174-81. doi: 10.18553/jmcp.2017.23.2.174

15. American Society of Clinical Oncology. QOPI-related measures. 2020. Accessed September 17, 2020. https://practice. asco.org/quality-improvement/qualityprograms/quality-oncology-practiceinitiative/qopi-related-measures

16. Pharmaceutical Research and Manufacturers of America. Patientreported outcome performance measures: current environment and next steps. December 14, 2017. Accessed September 17, 2020. https://www.phrma.org/report/ patient-reported-outcome-performancemeasures

17. Centers for Medicare \& Medicaid Services. Quality programs. August 24, 2017. Accessed September 17, 2020. https://www.cms.gov/Medicare/ Quality-Initiatives-Patient-AssessmentInstruments/MMS/Quality-Programs.html
18. Centers for Medicare \& Medicaid Services. OCM-4a Measure Specifications Effective 07.01.2019_v1.4.1. July 1, 2019. Accessed October 12, 2020. https:// innovation.cms.gov/media/document/ ocm-jul-dec2019-measurement-periodagg-result-rptg.

19. Centers for Medicare \& Medicaid Services. OCM-5 Measure Specifications Effective 07.01.2019_v1.4.1. July 1, 2019. Accessed October 12, 2020. https:// innovation.cms.gov/media/document/ ocm-jul-dec2019-measurement-periodagg-result-rptg.

20. Centers for Medicare \& Medicaid Services. OCM performance-based payment methodology version 6 . February 2020. Accessed September 17, 2020. https://innovation.cms.gov/Files/x/ocmpp3beyond-pymmeth.pdf

21. Centers for Medicare \& Medicaid Services. Proposed radiation oncology (RO) model. July 10, 2019. Accessed September 17, 2020. https://www.cms. gov/newsroom/fact-sheets/proposedradiation-oncology-ro-model

22. Centers for Medicare \& Medicaid Services. Medicare program: specialty care models to improve quality of care and reduce expenditures. July 18, 2019. Accessed September 17, 2020. https://www.federalregister.gov/documents/2019/07/18/2019-14902/medicare-program-specialty-care-modelsto-improve-quality-of-care-and-reduceexpenditures\#p-411

23. Centers for Medicare \& Medicaid Services. Oncology care first model: informal request for information. November 25, 2019. Accessed September 17, 2020. https://innovation.cms.gov/ files/x/ocf-informalrfi.pdf

24. U.S. Department of Health \& Human Services. Physician-focused payment model technical advisory committee report to the secretary. January 29, 2019. Accessed September 17, 2020. https:// aspe.hhs.gov/system/files/pdf/255731/ PTACReportIOBS.pdf 
25. U.S. Department of Health \& Human Services. MASON-making accountable sustainable oncology networks. February 18, 2018. Accessed September 17, 2020. https://aspe.hhs.gov/system/files/ pdf/255906/ProposalIOBS.pdf

26. PatientEngagementHIT. NCQA selects payer for patient-reported outcomes measures project. September 27, 2018. Accessed September 17, 2020. https:// patientengagementhit.com/news/ncqaselects-payer-for-patient-reported-outcomes-measures-project

27. National Committee for Quality Assurance. Oncology medical home standards and guidelines. January 22, 2019. Accessed September 17, 2020. https:// www.ncqa.org/programs/health-careproviders-practices/oncology-medicalhome/oncology-medical-home-recognition-program-retirement/

28. National Committee for Quality Assurance. Oncology medical home recognition: program retirement. 2020. Accessed September 17, 2020. https:// www.ncqa.org/programs/health-careproviders-practices/oncology-medicalhome/oncology-medical-home-recognition-program-retirement/

29. National Committee for Quality Assurance. PCSP standards and guidelines (2019 Edition, Version 3). July 1, 2020. Accessed September 17, 2020. http:// store.ncqa.org/index.php/catalog/product/view/id/3428/s/ncqa-pcsp-standards-and-guidelines-epub/

30. National Quality Forum. AHIP, CMS, and NQF partner to promote measure alignment and burden reduction. 2020. Accessed September 17, 2020. http:// www.qualityforum.org/cqmc/

31. Core Quality Measures Collaborative. Principles for core set measure selection. Accessed September 17, 2020. http:// www.qualityforum.org/WorkArea/linkit. aspx? LinkIdentifier $=$ id\&ItemID $=89885$

32. Centers for Medicare \& Medicaid Services. Meaningful measures hub. July 22, 2019. Accessed September 17, 2020. https://www.cms.gov/Medicare/ Quality-Initiatives-Patient-AssessmentInstruments/QualityInitiativesGenInfo/ MMF/General-info-Sub-Page
33. U.S. Department of Health and Human Services. HHS announces quality summit to streamline and improve quality programs across government. July 9, 2019. Accessed September 17, 2020. https:// www.hhs.gov/about/news/2019/07/09/ hhs-announces-quality-summit-streamline-improve-quality-programs-government.html

4. National Quality Forum. Quality positioning system. 2020. Accessed September 17, 2020. http://www.qualityforum.org/QPS/

35. ActiveHealth Management. About us. 2020. Accessed September 17, 2020. https://www.activehealth.com/about-us/ 36. HealthPartners. Total cost of care. 2020. Accessed September 17, 2020. https://www.healthpartners.com/hp/ about/tcoc/index.html

37. HealthPartners. About. 2020. Accessed September 17, 2020. https://www.healthpartners.com/about/

38. National Quality Forum. Consensus core set: medical oncology measures version 1.0. November 23, 2015. Accessed September 17, 2020. http://www.qualityforum.org/WorkArea/linkit.aspx?LinkIde ntifier=id\&ItemID $=88911$

39. Core Quality Measures Collaborative. CQMC core sets. 2020. Accessed September 17, 2020. https://www.qualityforum.org/CQMC_Core_Sets.aspx

40. Patient-Centered Outcomes Research Institute. Our programs. March 29, 2017. Accessed September 17, 2020. https:// www.pcori.org/about-us/our-programs

41. National Quality Forum. Measure evaluation criteria. 2020. Accessed September 17, 2020. http://www.qualityforum.org/ Measuring_Performance/Submitting_ Standards/Measure_Evaluation_Criteria.aspx

42. Smith A. NHS approves app for cancer related fatigue. PharmaTimes online. August 7, 2019. Accessed September 17, 2019. http://www.pharmatimes.com/ news/nhs_approves_app_for_cancer_ related_fatigue_1296534

43. Denis F, Basch E, Septans AL, et al. Two-year survival comparing web-based symptom monitoring vs routine surveillance following treatment for lung cancer. JAMA. 2019;321(3):306-07.
44. Lizée T, Basch E, Trémolières $\mathrm{P}$, et al. Cost-effectiveness of web-based patientreported outcome surveillance in patients with lung cancer. J Thorac Oncol. 2019;14(6):1012-20.

45. Centers for Medicare \& Medicaid Services. PPS-exempt cancer hospital reporting (PCHQR) program measures. Accessed September 17, 2020. https:// www.qualitynet.org/dcs/ContentServer?c =Page\&pagename=QnetPublic\%2FPage $\% 2$ FQnetTier2\&cid=1228774283195

46. Center for Medicare and Medicaid Innovation. Oncology care model other payer (OCM-OP) core measure set. September 14, 2020. Accessed September 17, 2020. https://innovation.cms.gov/ Files/x/ocm-otherpayercoremeasure.pdf

47. Center for Medicare and Medicaid Innovation. Oncology care model overview. February 2020. Accessed September 17, 2020. https://innovation.cms.gov/ Files/slides/ocm-overview-slides.pdf

48. National Quality Forum. Preventive care and screening: screening for depression and follow-up plan. 2020. Accessed September 17, 2020. http://www.qualityforum.org/QPS/0418

49. Centers for Medicare \& Medicaid Services. Explore measures \& activities: 2020 quality measures. 2020. Accessed September 17, 2020. https://qpp.cms.gov/ mips/explore-measures/quality-measure $\underline{\mathrm{s} \text { ?specialtyMeasureSet }=\text { Oncology } \% 2 \mathrm{FHe}}$ matology

50. Centers for Medicare \& Medicaid Services. Explore measures \& activities: oncology: medical and radiation-pain intensity quantified. 2020. Accessed September 17, 2020. https://qpp.cms.gov/ mips/explore-measures/qualitymeasures?specialtyMeasureSet $=$ Radiation\%200ncology

51. Centers for Medicare \& Medicaid Services. 2019 QCDR measure specifications version 7. October 11, 2019. Accessed September 17, 2020. https:// qpp-cm-prod-content.s3.amazonaws. com/uploads/430/2019\%20QCDR\%20 Measure\%20Specifications_v7.0.xlsx 